\title{
CDISC SDTM Implementation Guide Version 3.3
}

National Cancer Institute

\section{Source}

National Cancer Institute. CDISC SDTM Implementation Guide Version 3.3. NCI

Thesaurus. Code C161437.

The 3.3 version of the CDISC Study Data Tabulation Model (SDT M) implementation guide. 